\title{
Extinction of avoidance behavior: CS presentations with and without punishment
}

\author{
C. L. EISON AND J. M. SAWREY \\ SAN JOSE STATE COLLEGE
}

In $a$ by 3 factorial design, groups of rats were given 3 differing CS presentations with and without punishment during extinction of an alley avoidance response. Punishment and two methods of CS presentations were predicted to facilitate extinction. Amount of time required and total trials to extinction were dependent variables. All of the hypotheses were supported to some degree. The results lend support to the interpretation that CS develops fear arousing properties.

Mowrer (1947, 1956) and Stampfl (London, 1964) have indicated that emotional responses become conditioned to external cues in a conditioned avoidance situation. Whittleton, Kostansek, \& Sawrey (1965) found that extinction was facilitated in their Ss when they ran toward a CS rather than away from a CS. Longer CS presentations have been shown to facilitate extinction (Weinberger, 1965) as has the punishment of avoidance (Seligman \& Campbell, 1965).

The present investigation was concerned with the length of CS presentation, the presentation of a second CS between the start box and goal box, and the punishment of the last response made in the chain of avoidance responses. The hypotheses to be tested were: (1) The longer the CS duration during detainment in the start box the more the extinction of avoidance behavior will be facilitated. (2) A second presentation of the CS, which the $\mathrm{S}$ must run past during avoidance behavior, will facilitate extinction. (3) Punishment of the last response made in the sequence of avoidance responding will facilitate extinction.

Method

Subjects. The Ss were 48 experimentally naive male Sprague-Dawley rats, 90 to 110 days of age.

Apparatus. The apparatus consisted of a wood alley runway $7 \mathrm{ft}$. long with a grid floor of $1 / 8$ in. brass rods on $5 / 8$ in. centers mounted in Plexiglas. The alley was 6 in. wide and 8 in. high. Plexiglas covered the top except for sliding wood lids that covered the two end boxes. A Plexiglas door was used to contain the Ss in the start box. The CS (725 Dixie Buzzers) intensity within the start box was $84 \mathrm{~dB}$. One buzzer used at the start box was placed on the outside against the wood $4 \mathrm{in}$. from the top of the alley

Shock was delivered by an Applegate Constant Current stimulator set at $1.0 \mathrm{ma}$ throughout the experiment. The current was fed through a Grason-Stadler 18 pole grid scrambler.

Procedure. Ss were handled during the 30 days previous to the experiment, which ran for 20 days. Ss were trained and tested in one session. $S$ was placed in the start box with the door closed. For 10 trials the start box
CS was sounded for 4 sec., the door was opened and shock was presented to the grid. The CS and UCS were terminated when the $S$ reached the goal box; the goal box door was then closed. For the next 10 trials the $S$ received avoidance training. The CS was presented for 3 sec.; the UCS was presented 7 sec. after the CS onset. During the next 10 trials the CS was presented for 2 sec. and then turned off as soon as the door was completely open. The UCS was turned on 6 sec. after the CS onset.

After this preliminary training $S s$ were run to a criterion of 9 out of 10 successful avoidance trials in the following manner: The $S$ was placed in the start box for 5 sec. The startbox CSwas presented for $2 \mathrm{sec}$. and turned off after the door was completely opened. The UCS was presented 6 sec. after the CSonset. If the $S$ ran into the goal box before the 6 sec.lapse between CS and UCS onset he made an avoidance response. The intertrial interval was $30 \mathrm{sec}$. All Ss received a minimum of 39 trials to criterion.

Extinction. During the extinction trials the Ss never received shock in the start box or alley. The extinction trials began $30 \mathrm{sec}$. after training criterion was met. Ss were divided into six groups, eight per group. During the extinction trials three of the groups received shock ( 1 ma for 1 sec.) in the goal box when they completed an avoidance run; three groups did not receive this treatment. Three different presentations of CS were employed.

Group 1: The $S$ was placed in the start box and after $3 \mathrm{sec}$. the buzzer CS was presented for $2 \mathrm{sec}$. The door was opened $5 \mathrm{sec}$. after the $S$ was placed in the box and at the moment of CS cessation. In all groups the door was open at the time the start box CS was turned off. These Ss (CS-no shock group) received no shock in the goal box and were considered a regular extinction group.

Group 4: This group was the "CS only-shock" group. The procedure was the same as for group 1 except that the $S$ received 1 ma of shock for $1 \mathrm{sec}$. if he ran into the goal box.

Group 2: This was the "double CS-no shock" group. After the $\mathrm{S}$ was placed into the start box, the CS was presented for 2 sec.; 1 sec. elapsed and another 2 sec. of CS was presented at which time the door was opened. These Ss received no shock in the goal box.

Group 5: This was the "double CS-shock" group. This group received the same treatment as group 2 except the Ss received shock in the goal box if they made an avoidance response ( $1 \mathrm{ma}$ for 1 sec.).

Group 3: This was the "second CS-no shock" group. Two sec. after the $S$ was placed into the start box the 
Table 1. Mean Time to Extinction in Seconds

\begin{tabular}{lccc} 
& CS only & Second CS & Second CS \\
\hline No shock & 863 & 705 & 432 \\
Shock & 329 & 326 & 345 \\
\hline
\end{tabular}

CS was presented for $3 \mathrm{sec}$. At 5 sec. the door was opened. If the animal ran down the alley and his head went past the point of the alley buzzer, the second CS was presented for 1 sec. No shock was administered in the goal box.

Group 6: This was the "second CS-shock" group. The same procedure was applied to this group as for group 3 except that the animals received shock if they ran into the goal box ( 1 ma for 1 sec.). The number of trials and time to extinction criterion were recorded for each animal.

\section{Resulfs}

The total time to extinction for each group was treated by a two-way analysis of variance for uncorrelated means to test for the effects of different CS presentations and the effect of shock. A CS effect was significant $(\mathrm{F}=16.689, \mathrm{p}<.005)$ in the direction predicted.

Shock effect was highly significant ( $F=127.085$, $p<.005)$ as was the interaction effect $(F=19.657$, $\mathrm{p}<.005)$. The no-shock groups extinguished after a significantly longer period of time.

A $t$ test for uncorrelated means for a small sample was used to test the difference between the "CS onlyno shock" groups to test Hypothesis 1. The CS only group took significantly more time $(p<.01)$ to extinguish.

Number of trials to extinction was treated by a twoway analysis of variance. Shock effect was highly significant $(F=104.890, \mathrm{df}=1 / 42, \mathrm{p}<.005)$. The no-shock groups took more trials to extinguish. CS effect was highly significant $(F=6.933$, $d f=2 / 42, p<.005)$. Interaction effect was highly significant $(F=10.944, \mathrm{df}=2 / 42$, $\mathrm{p}<.005)$.

A $t$ test between the "CS only-no shock" and the "double CS-no shock" groups was not significant. The obtained t of 2.579 between the "double CS-shock" and the "second CS-shock" groups was significant $(p<.05)$. Discussion

Punishment of the learned avoidance had an overriding inhibitory effect upon behavior. Shock in the goal box facilitated the extinction to a similar degree in all groups. Hypothesis 3 concerning the effect of punishing the last response made was supported.
Table 2. Mean Trials to Extinction

\begin{tabular}{lccc} 
& CS oniy & Double CS & Second CS \\
\hline No shock & 65.3 & 60.6 & 33.1 \\
Shock & 17.5 & 16.5 & 20.6 \\
\hline
\end{tabular}

Within the no-shock groups, the CS-only group took longer to extinguish than the other CS groups. This finding meets the prediction in hypothesis 1 regarding the length of CS presentation. The longer the $\mathrm{S}$ was exposed to CS the more likely competing responses would be associated with the CS and the more rapidiy extinction occurred. The double CS group took longer in both time and trials to extinguish than the second CS group. The response of running past the second buzzer initially made the Ss respond more rapidly. They soon stopped responding, however. The extinction of this group was more abrupt than for the first two groups and it appeared that the act of running toward the buzzer was punishing. Their extinction data looked more like the shock groups' than the no-shock groups'. These results agree with the prediction regarding the second CS presentation (hypothesis 2) and lend support to the idea that the CS may be fear a rousing.

The CS conceived as a noxious stimulus grossly changes the stimulus situation for the animal. These results can be interpreted as lending support to Mowrer's hypothesis.

The change from the training procedure to the extinction procedure produces different cues in the apparatus. The changed stimulus situation results in a modification of behavior.

\section{References}

London, P. The modes and morals of psychotherapy. New York: Holt, Rinehart and Winston, Inc., 1964.

Mowrer, O. H. On the dual nature of learning: a reinterpretation of "conditioning" and "problem solving." Harv. educ. Rev., 1947. $17,102-148$.

Mowrer, o. H. Two-factor learning theory reconsidered, with special reference to secondary reinforcement and the concept of habit. J. comp. physiol. Psychol., 1965, 59, 295-297.

Seligman, M., \& Campbell, B. A. Effect of intensity and duration of punishment on extinction of an avoidance response. J. comp. physiol. Psychol., 1965, 59, 295-297.

Weinberger, N. M. Effect of detainment on extinction of avoidance responses. J. comp. physiol. Psychol., 1965, 59, 135-138.

Whittleton, J. C., Kostansek, D. J., \& Sawrey, J. M. CS directionality and intensity in avoidance learning and extinction. Psychon. Sci., 1965, 3, 415-416. 